\title{
Transcriptome analysis provides genome annotation and expression profiles in the central nervous system of Lymnaea stagnalis at different ages
}

Martina Rosato ${ }^{1,2}$, Brittany Hoelscher ${ }^{1,2}$, Zhenguo Lin ${ }^{1}$, Chidera Agwu ${ }^{1}$ and Fenglian $\mathrm{Xu}^{1,2,3^{*}}$

\begin{abstract}
Background: The pond snail, Lymnaea stagnalis (L. stagnalis), has served as a valuable model organism for neurobiology studies due to its simple and easily accessible central nervous system (CNS). L. stagnalis has been widely used to study neuronal networks and recently gained popularity for study of aging and neurodegenerative diseases. However, previous transcriptome studies of $L$. stagnalis CNS have been exclusively carried out on adult $L$. stagnalis only. As part of our ongoing effort studying L. stagnalis neuronal growth and connectivity at various developmental stages, we provide the first age-specific transcriptome analysis and gene annotation of young (3 months), adult (6 months), and old (18 months) L. stagnalis CNS.

Results: Using the above three age cohorts, our study generated 55-69 millions of 150 bp paired-end RNA sequencing reads using the Illumina NovaSeq 6000 platform. Of these reads, $\sim 74 \%$ were successfully mapped to the reference genome of $L$. stagnalis. Our reference-based transcriptome assembly predicted 42,478 gene loci, of which 37,661 genes encode coding sequences (CDS) of at least 100 codons. In addition, we provide gene annotations using Blast2GO and functional annotations using Pfam for 95\% of these sequences, contributing to the largest number of annotated genes in L. stagnalis CNS so far. Moreover, among 242 previously cloned $L$. stagnalis genes, we were able to match $\sim 87 \%$ of them in our transcriptome assembly, indicating a high percentage of gene coverage. The expressional differences for innexins, FMRFamide, and molluscan insulin peptide genes were validated by real-time qPCR. Lastly, our transcriptomic analyses revealed distinct, age-specific gene clusters, differentially expressed genes, and enriched pathways in young, adult, and old CNS. More specifically, our data show significant changes in expression of critical genes involved in transcription factors, metabolisms (e.g. cytochrome P450), extracellular matrix constituent, and signaling receptor and transduction (e.g. receptors for acetylcholine, N-Methyl-D-aspartic acid, and serotonin), as well as stress- and disease-related genes in young compared to either adult or old snails.
\end{abstract}

\footnotetext{
* Correspondence: fenglian.xu@slu.edu

'Department of Biology, College of Arts and Sciences, Saint Louis University, St. Louis, MO, USA

${ }^{2}$ Henry and Amelia Nasrallah Center for Neuroscience, Saint Louis University, St. Louis, MO, USA

Full list of author information is available at the end of the article
}

C C The Author(s). 2021 Open Access This article is licensed under a Creative Commons Attribution 4.0 International License, which permits use, sharing, adaptation, distribution and reproduction in any medium or format, as long as you give appropriate credit to the original author(s) and the source, provide a link to the Creative Commons licence, and indicate if changes were made. The images or other third party material in this article are included in the article's Creative Commons licence, unless indicated otherwise in a credit line to the material. If material is not included in the article's Creative Commons licence and your intended use is not permitted by statutory regulation or exceeds the permitted use, you will need to obtain permission directly from the copyright holder. To view a copy of this licence, visit http://creativecommons.org/licenses/by/4.0/. The Creative Commons Public Domain Dedication waiver (http://creativecommons.org/publicdomain/zero/1.0/) applies to the data made available in this article, unless otherwise stated in a credit line to the data. 
Conclusions: Together, these datasets are the largest and most updated L. stagnalis CNS transcriptomes, which will serve as a resource for future molecular studies and functional annotation of transcripts and genes in $L$. stagnalis.

Keywords: Lymnaea stagnalis, CNS, Transcriptome, Gene annotation, Different ages, Neurodevelopment, Synaptic genes, Disease-related genes

\section{Background}

The pond snail Lymnaea stagnalis (L. stagnalis) belongs to the phylum Mollusca, class Gastropoda [1]. Like its counterpart, the sea slug Aplysia californica (A. californica), L. stagnalis has served as an important mollusc model organism for the neurobiology field since the 1970s due to its simple central nervous system (CNS), well characterized network, large and easily accessible neurons, and a relatively short life cycle [2]. L. stagnalis CNS contains a total of 20,000-25,000 neurons organized in a ring of 11 connected ganglia. The neurons are large in size (up to $\sim 100 \mu \mathrm{m}$ in diameter versus $\sim 15-$ $25 \mu \mathrm{m}$ in diameter of vertebrate central neurons) $[2,3]$ and easily recognizable, making them a perfect target for in vitro and in vivo studies. Many studies have used this model to investigate the fundamental mechanisms of neuronal networks involved in various behaviours including feeding $[4,5]$, respiration $[6,7]$, locomotion $[8$, 9], and reproduction [10, 11]. Studies have also focused on high cognitive behaviours, including learning and memory [12-15], as well as deciphering cellular mechanisms of synapse formation and synaptic plasticity during development [16-18]. L. stagnalis has also recently gained increasing popularity for the investigation of brain aging and neurodegenerative diseases such as Parkinson's disease and Alzheimer's disease [19-23]. It is important to note that comparative studies have highlighted several human homologs involved in aging and neurodegenerative disease in both $A$. californica and L. stagnalis [24-26], showing the great potential for future molecular insights into brain aging and pathology using these unique mollusc models. More importantly, a recent study has successfully established the use of CRISPR/Cas9 in L. stagnalis embryos [27], further underscoring the high feasibility of $L$. stagnalis for genetic studies.

Despite the importance of L. stagnalis to brain network, behaviour, and development studies, genetic information is mostly limited to the identification and cloning of individual genes. Only in the past decade several groups have tried to study the $L$. stagnalis transcriptome using expressed sequence tags (EST) [28-30] and RNA sequencing (RNA-Seq) [31, 32]. However, all these studies have focused on only one developmental time point, predominantly in adults. Considering the increasing use of L. stagnalis for brain aging and pathology research [24], updated transcriptome datasets and gene annotations including old or aging snail CNS are critically needed. Studies of transcriptional changes in brains of animals at various ages will provide important molecular insights into brain development, aging, pathology, and evolution. Spatial and/or temporal transcriptome analyses of brains and other tissues have been carried out in human [33, 34], rats [35], mice [36], chicken [37], zebrafish [38], and birds [39] among others. All these studies have contributed to our understanding of the molecular basis of brain development. Invertebrates have also been utilized for study of development and aging. Developmental transcriptomes of well-established invertebrate models such as Caenorhabditis elegans (C. elegans) $[40,41]$ and Drosophila melanogaster (D. melanogaster) [42] have been reported. Recent efforts have also focused on the transcriptome of aging $D$. melanogaster [43, 44] and C. elegans [45], aiming to reveal molecular mechanisms of longevity or aging trajectories.

In mollusca, the developmental (embryonic, larval, and metamorphic) transcriptome of A. californica [46] and maternal ( 1 to 2 cell and $\sim 32$ cell) transcriptome of $L$. stagnalis have been conducted [47]. These studies shed novel insights into conserved sets of genes and pathways in early development. However, these studies failed to inform how these genes or other sets of genes are regulated in later stages of life, such as after animals are fully matured and aged. Although transcriptome changes in a subset of sensory neurons involved in tail-withdrawal reflex in matured and aged $A$. californica have been reported [48], transcriptome changes of entire CNS in young, mature, and aged A. californica and L. stagnalis have not been carried out. Understanding transcriptome changes in the entire CNS, but not a confined set of neurons, will shed light in the overall genetic profiles for nervous system development and aging, as well as for regulation of all ranges of animal behaviours. Such studies are critical for our complete understanding and comparative studies of age- or species- specific molecular strategies that are key to the evolution, survival, and function of both invertebrate and vertebrate.

To this end, in the present study, we provide whole transcriptome analysis in L. stagnalis CNS from three different ages: 3 months (young), 6 months (adult), and 18 months (old). This is the first time that changes in CNS transcriptome profiling during brain development, maturation, and aging in L. stagnalis are analyzed. Our RNA-Seq, using Illumina NovaSeq 6000 platform, 
produced 56-69 millions of $150 \mathrm{bp}$ paired-end reads, and $74 \%$ of these reads were mapped to the draft genome of L. stagnalis. We provide gene annotations for 32,288 coding sequences with a minimum of 100 codons, contributing to the largest number of annotated genes for the L. stagnalis genome to date. Furthermore, our data reveal age-specific, differentially expressed genes and enriched pathways in young, adult, and old CNS. Among those, we have highlighted genes implicated in neural development and synaptic function, as well as stress and disease conditions.

\section{Results}

L. stagnalis CNS transcriptome sequencing, assembly, and gene annotation

RNA-Seq was performed using CNS samples from young ( 3 months old), adult (6 months old), and old (18 months old) snails (Fig. 1A), with four biological replicates in each group and ten snails in each replicate. $L$. stagnalis has a relatively short life cycle, with a life expectancy of about 1.5 to 3 years [49]. The embryonic stage of the snail lasts for around 2 weeks, and eggs are contained in gelatinous masses that are accessible for genetic manipulation. After hatching, young snails reach sexual maturity at around 4 to 6 months of age, and senescence starts after $7-8$ months $[49,50]$. Therefore, the

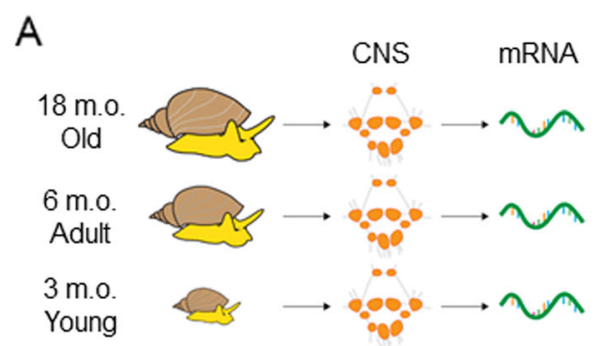

C
B

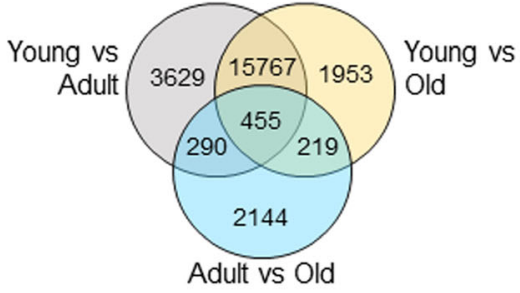

- n.s. $\log 2 \mathrm{FC} \bullet p$-value $\bullet p$-value and log2 FC

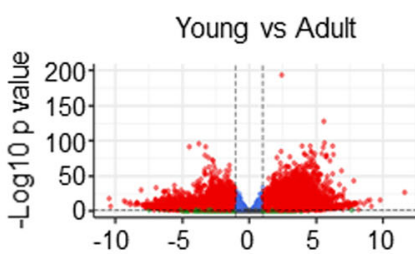

Young vs Old

Adult vs Old
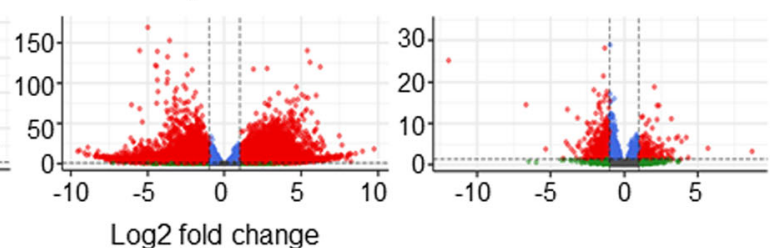

E
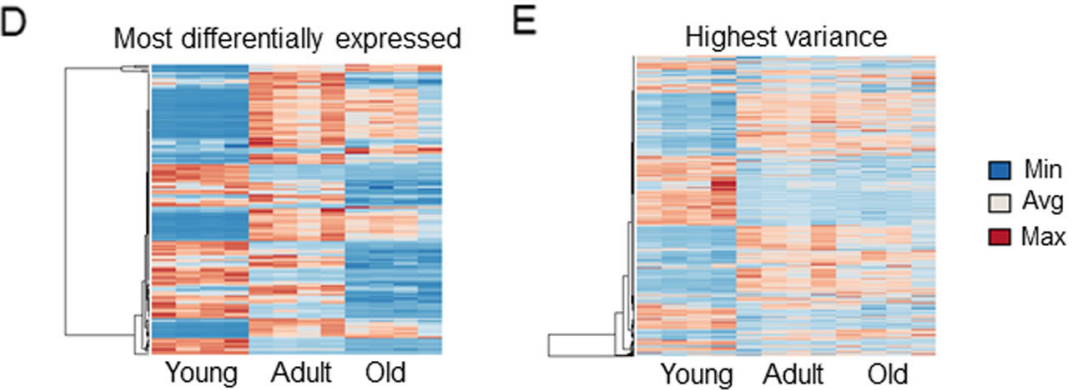

Fig. 1 Transcriptomes pairwise comparisons reveal a specific pattern of gene expression in L. stagnalis CNS. A For transcriptome analysis, mRNA was extracted from the CNS of young ( 3 months old), adult ( 6 months old), and old ( 18 months old) snails. For each age group, four different biological replicates $(n=4)$, each with mRNA samples from the CNS of 10 snails, were used. B Venn diagram showing the significantly differentially expressed genes in each pairwise comparison and the overlap among them. The diagram clearly shows that young CNS transcriptome has more significantly differentially expressed genes compared to adult and old. (FDR adjusted $p$-value $p<0.05$; log 2 fold change $>$ |1|). C Volcano plot of each pairwise comparison. The plots are color-coded based on the log2 fold change (green dots), and corrected $p$-value (blue dots). Red dots highlight genes that are significant and whose expression is highly changed (FDR adjusted $p$-value $p<0.05$; log2 fold change $>|1|)$. Volcano plots of the comparison between adult and old CNS transcriptome shows less differentially expressed genes, by either $p$ value or log2 fold-change, compared to the pairwise comparison of young versus adult or old transcriptome. D, E Heatmap of the most differentially expressed genes in all pairwise comparisons (FDR adjusted $p$-value $p<0.05$ ) and the genes with the highest variance (top 2000 genes), respectively. Both heatmaps show a distinct pattern of gene expression in the CNS transcriptome of young snails compared to adult and old 
3-month-old age in our study represents a rapid developing and sexual immature stage, the 6-month-old age represents a fully, sexually mature stage, and 18-monthold represents an aging stage $[49,50]$.

Our RNA-Seq data provides a good sequencing depth, with a total number of reads ranging from 55,601,129 $(56 \mathrm{M})$ to $69,121,300(69 \mathrm{M})$ and an average overall alignment rate is $\sim 74 \%$ (Table 1 ). A total of 61,994 transcripts from 42,478 genes are identified. Of those genes, 37661 encode for proteins of at least 100 amino acids. To provide functional annotations for inferred L. stagnalis genes, we retrieved proteomic sequences of nine molluscan species from the NCBI RefSeq database (See Methods). Our transcript assembly and gene function annotation provide the first genome annotation for $L$. stagnalis with 32,182 out of 33,786 unique transcripts (95.25\%) that have matched Pfam domain and/or homologs (provided as Additional file 2 in gff3 format).

\section{Transcriptional clustering pattern in the CNS of young, adult, and old $L$. stagnalis}

Our principal component analysis (PCA) of $\log 2$ of the raw counts for the 12 transcriptomes (three age groups, four replication samples per age group) form three major clusters (Additional Figure 1A), corresponding to the three age groups of samples. The majority of biological replicates cluster together, suggesting that expression profiles are more similar in animals belonging to the same-age cohort. The first principal component (PC1), which accounts for $68.12 \%$ of the variance in the data, provides separation between young and the other two groups (adult and old). The second principal component (PC2) only accounts for $7 \%$ of the variance, serving as a discriminator between adult and old transcriptomes. These patterns suggest that there are constitutive differences in transcriptomes between young and adult/old CNS, while adult and old CNS transcriptomes are more similar to each other. These results are consistent with pairwise Pearson correlations between these samples (Additional Fig. 1B).

To identify genes that are differentially expressed (DE) during the development of the CNS, we conducted pairwise comparisons of transcriptomes for the three groups of samples: young vs. adult, young vs. old, and adult vs. old. We identify 20,141 significant DE genes between young and adult groups; 18,394 DE genes between young and old groups; and only 3108 significant DE genes between adult and old groups (FDR adjusted $p$ value $p<0.05$; $\log 2$ fold change $>|1|$ ) (Fig. 1B,C). Interestingly, only $455 \mathrm{DE}$ genes are present in all comparisons. Together, these analyses suggest that most changes in CNS development occur pronouncedly during transitions from young to adult, and less changes occur during transitions from adult to old.

\section{Analysis of the DE genes confirms distinct gene} expression patterns in young, adult, and old $L$. stagnalis Next, we selected the top 100 genes that, among those sequences with at least 100 codons, are the most DE based on their adjusted $p$-values in each pairwise comparison. After assessing a partial overlap between each pairwise comparison, a total of 143 unique most DE genes are used. Heatmap analysis of FPKM expression shows a different expression pattern among age groups (Figs. 1D,E). Specifically, consistent with the above PCA, individual replicates exhibit very similar regulation patterns within the same age cohort (Fig. 1D). Overall, the adult animal transcriptome shows more highly expressed genes, while around half of genes in young and the majority of genes in old exhibit low expression. The heatmap pattern also shows that 1) most genes with low expression in young animals are highly expressed in adult and remain high in

Table 1 Mapping summary of RNA-Seq data

\begin{tabular}{|c|c|c|c|c|}
\hline Sample ID & Raw reads & Pairs & overall alignment rate & aligned concordantly exactly 1 time \\
\hline$\overline{\mathrm{A} 1}$ & $111,202,258$ & $55,601,129$ & $73.64 \%$ & $32,393,971(58.26 \%)$ \\
\hline A2 & $117,009,046$ & $58,504,523$ & $70.58 \%$ & $32,531,948(55.61 \%)$ \\
\hline A3 & $126,008,938$ & $63,004,469$ & $68.96 \%$ & $33,453,481(53.10 \%)$ \\
\hline A4 & $118,371,182$ & $59,185,591$ & $66.10 \%$ & $29,961,867(50.62 \%)$ \\
\hline A5 & $120,837,330$ & $60,418,665$ & $77.56 \%$ & $37,389,888(61.88 \%)$ \\
\hline A6 & $130,596,268$ & $65,298,134$ & $78.03 \%$ & $40,020,465$ (61.29\%) \\
\hline A7 & $138,242,600$ & $69,121,300$ & $76.80 \%$ & $41,408,979(59.91 \%)$ \\
\hline A8 & $120,985,900$ & $60,492,950$ & $77.88 \%$ & $36,964,875(61.11 \%)$ \\
\hline A9 & $114,785,564$ & $57,392,782$ & $76.97 \%$ & $34,327,672(59.81 \%)$ \\
\hline A10 & $111,292,186$ & $55,646,093$ & $76.08 \%$ & $33,245,908$ (59.75\%) \\
\hline A11 & $125,842,254$ & $62,921,127$ & $77.27 \%$ & $38,379,882$ (61.00\%) \\
\hline $\mathrm{A} 12$ & $120,566,284$ & $60,283,142$ & $75.40 \%$ & $35,319,113$ (58.59\%) \\
\hline
\end{tabular}


old; 2) most highly expressed genes in young animals have low expression in adult and become further down-regulated in old animals; 3) only a few clusters contain genes whose expression increases from young to adult and then decreases from adult to old (Fig. 1D). We also looked at the top 2000 genes with the highest variance across all samples. The heatmap in Fig. 1E shows 1) variance in DE gene expression, again, separates young transcriptome from transcriptomes of adult and old, and the highest variance occurs in the young animal transcriptome; 2) two big clusters of genes increase in expression from young to adult CNS transcriptome and retain relatively high expression in old; 3) two big clusters of genes decrease in expression from young to adult CNS transcriptome and further lower their expression in old; 3) a few small clusters of genes increase expression from young to adult and then decrease from adult to old. Together, these data indicate that there are distinct changes of transcript profiling across life stages of animals. Next, we sought to study what sets of DE genes and related pathways are involved in the expression patterns across different life stages.

\section{Gene ontology analysis}

We performed GO annotation with Blast2GO [51] for the 37,661 transcripts that encode proteins with at least 100 amino acids (see Methods). A total of 32,288 transcripts (or genes) were successfully annotated with GO terms. GO enrichment analysis was performed for DE genes in: all pairwise comparisons (455 genes), young compared to adult CNS transcriptome $(20,141)$, young compared to old CNS transcriptome $(18,394)$, and adult

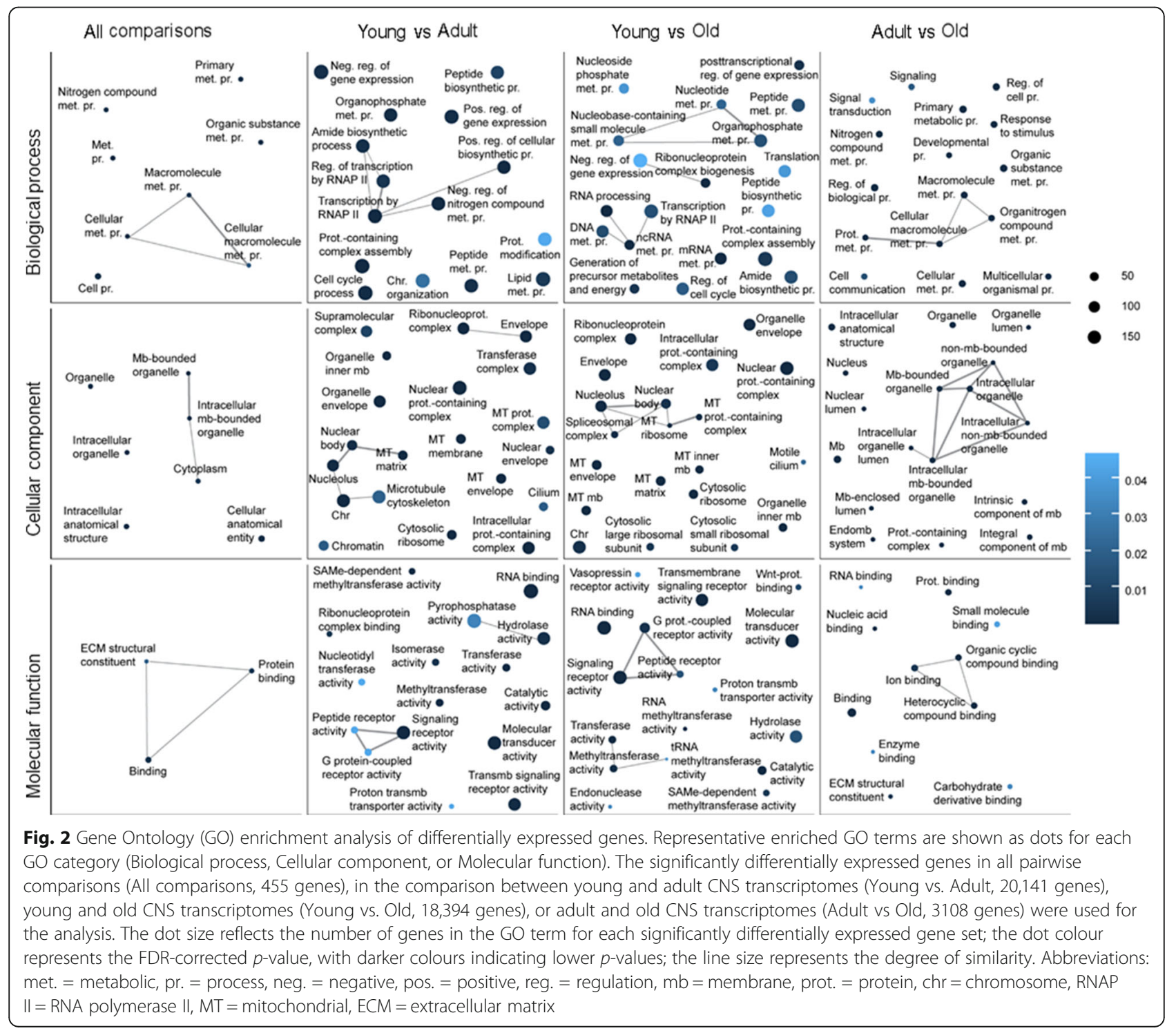


compared to old CNS transcriptome (3108) (FDR adjusted $p$-value $p<0.05$; $\log 2$ fold change $>|1|$ ) (Fig. 2). As expected from the huge overlap among significant $\mathrm{DE}$ genes, GO enrichment from young compared to adult and young compared to old groups partially overlap (Fig. 2). In these two comparisons, the common GO terms in biological process are related to gene expression (transcription by RNA polymerase II and positive or negative regulation of gene expression). Genes in this pathway include the Rho GTPases cdc42 and tyrosineprotein kinase SRK2-like and several transcription factors, such as Sox14, Dp1, Sp4, and NF-kB. GO terms in cellular components are related to mitochondrial and ribosome pathways (mitochondrial ribosome, mitochondrial matrix, mitochondrial membrane, cytosolic ribosome, and ribonucleoprotein complex). These pathways include the $40 \mathrm{~S}$ and $60 \mathrm{~S}$ ribosomal genes, ubiquinone genes such as NADH dehydrogenase, and several mitochondrial enzymatic genes, including superoxide dismutase, pyruvate dehydrogenase, propionyl CoA carboxylase, and isobutyryl CoA dehydrogenase. Finally, GO terms in molecular function are related to signalling receptor and signalling transduction pathways (signalling receptor activity, G protein-coupled receptor activity, and transmembrane signalling receptor activity). Among the signalling receptor pathways, we can find many genes coding for neurotransmitter receptors, like the $\mathrm{N}$ methyl-D-aspartate (NMDA) receptor, dopamine receptor, serotonin receptor (5-HT), gamma-aminobutyric acid (GABA) B receptor, acetylcholine receptor (AChR), FMRFamide receptor, octopamine receptor and orexin receptor. The common enriched metabolic, mitochondrial, and ribosomal pathways suggest that transcripts engaged in cellular metabolic, energy production, and protein synthesis activity are actively regulated in the CNS of snails.

When we look more in depth in the DE genes whose expression is significantly changed at all pairwise comparison, we discovered that the enriched GO terms include biological processes that are related to metabolism of nitrogen compounds, organic substances, macromolecules, and cellular macromolecules. The cellular component GO enrichment highlights the importance of organelle, intracellular organelle, and intracellular anatomical structure. Finally, molecular function GO enrichment includes extracellular matrix structural constituents and protein binding pathway. More specifically, among the most significant DE genes (FRD-corrected $p$-value) we can find several collagens sequences, most of which are down-regulated in old CNS snails compared to young and adult. Two cytochrome P450 genes (CYP2C3 and CYP2U1) have opposite pattern of gene expression, with the CYP2C3 being highly expressed in young snails while the CYP2U1 has its higher expression in old animals. Other highly significant genes include the neuronal growth factor neurotrophin-3-like whose expression is increasing from young to adult to old snail and the signaling molecule rac GTPase-activating protein 1-like that has a pattern of decreasing expression from young to adult to old animals. A table with the DE genes in all pairwise comparison that have a Blast2GO match is provided in Additional Table 4.

To gain further insights into what specific sets of $\mathrm{DE}$ genes are changed from young to adult to old snail CNS, we analysed the top100 DE genes used in Fig. 1D and examined their associated GO terms. A complete list of genes, their $\log 2$ fold change value, FDR-corrected $p$ values, descriptions, and GO terms are provided in Additional Table 5. We found that genes significantly increased from young to adult and remain elevated in old animals, including those involved in receptor signalling activity (e.g. NMDA receptor NR1 and NR2, Mollusc insulin-related peptide MIP, and Notch 3 receptors), signalling transduction mechanism (serine/threonine protein kinase TAO1-like TAOK1, protein kinase A PKA, and serine/threonine-protein phosphatase 2A PIPA), synaptic vesicle proteins (e.g. synaptotagmin 1 and 4), ion channels (e.g. voltage-gated $\mathrm{K}^{+}$channels Kv2.1a KCNB1), metabolism (pyruvate kinase PKM-like isoform X3 PKM and phosphopractokinase-like PFKM), membrane/membrane bound organelles (e.g. reticulon-3-A like and fat cadherin), transcription and translation (poly [ADP-ribose] polymerase 14-like gene PARP and translation initiation factor eIF-2 EIF2B4), and peptides and peptide enzymes (Titin-like X2 TTN and Peptidase C1like). Interestingly, there are only a few DE genes that are significantly increased from adult to old animals. These include monooxygenase/oxidoreductase active (CYP2U1), cysteine dioxygenase type (CD01), and endoglucanase E-4 like and A-like. Genes that are highly expressed in young and then significantly decrease in adult and old animals include ECM structure constituents (e.g. collagen $2 \mathrm{~A} 1$, collagen $1 \mathrm{~A} 1$, and fibril-forming collagen 2-chatin like). When comparing expression of genes in adult and old, we found that most genes exhibit significantly lower expression in old animals. These include stress and immune factors (dual oxidase 2-like DUOX2, oxidase activity cytochrome P450 CYP10, suppressor of cytokine signalling 2 SOCS2, and heat shock protein $60 \mathrm{HSP} 60), \mathrm{Ca}^{2+}$ binding $\left(\mathrm{Ca}^{2+} / \mathrm{CaM}\right.$-serine kinase CASK), protein ubiquitin (Myc binding protein MYCBP2 and ubiquitin-protein ligase E3A), and membrane and cellular entity (cadherin, adhesion G-protein coupled receptor L2 like GPCRL2, and disintegrin). Several above mentioned, stress-related genes and their expressions (TPM) in young, adult, and old L. stagnalis CNS are shown in Additional Fig. 2. 


\section{KEGG analysis}

Using Blast2GO [51] we also loaded KEGG [52-54] pathways for 37,661 transcripts that encode proteins with at least 100 amino acids (see Methods). A total of 1159 transcripts (or genes) were successfully associated with KEGG pathways. The most representative KEGG pathways in the overall transcriptome include purine metabolism, glycerophospholipid metabolism, cysteine and methionine metabolism, and amino sugar and nucleotide sugar metabolism (Fig. 3). Furthermore, KEGG enrichment analysis was performed for DE genes in: all pairwise comparisons (455 genes), young compared to adult CNS transcriptome $(20,141$, young compared to old CNS transcriptome $(18,394)$, and adult compared to old CNS transcriptome (3108) (FDR adjusted $p$-value $p<0.05$; $\log 2$ fold change $>|1|)$. The all pairwise comparison and adult compared to old comparison produced significant enrichment for the pathways of thiamine metabolism (all $p=2.38 \times 10^{-5}$, adult vs old $p=0.00$ ) and purine metabolism (all $p=0.01$, adult vs old $p=0.06$ ).

\section{qPCR studies confirm differential gene expression identified by RNA-Seq data}

We next performed qPCR to validate gene expression revealed by RNA-Seq for a few genes that are previously cloned by us (i.e. gap junction-forming innexin genes) [17] or others (i.e. FMRFamide and MIP genes) [55-57]. As shown in Fig. 4A,B, both RNA-seq data and qPCR data show a similar pattern of expression over ages for each gene. More specifically, $\operatorname{In} x 1$ has a significantly lower expression level in young animals compared to adult and old (RNA-Seq FDR adjusted $p$-value young vs adult $p=5.95 \times 10^{-7}$, young vs old $p=3.73 \times 10^{-6}$; qPCR Turkey's post-hoc test young vs adult $p=0.00$ young vs old $p=0.00)$. In $x 4$ also has similar trends in gene expression in both RNA-Seq and qPCR, but it is expressed significantly lower in the young animals only in the qPCR data (RNA-Seq FDR adjusted $p$-value young vs adult $p=0.39$, young vs old $p=0.39$; qPCR Turkey's post-hoc test young vs adult $p=0.00$, young vs old $p=$ $0.00)$. Similar to innexin genes, both RNA-Seq and qPCR data for FMRFamide and MIP genes show comparable pattern of expression over ages. More specifically, both

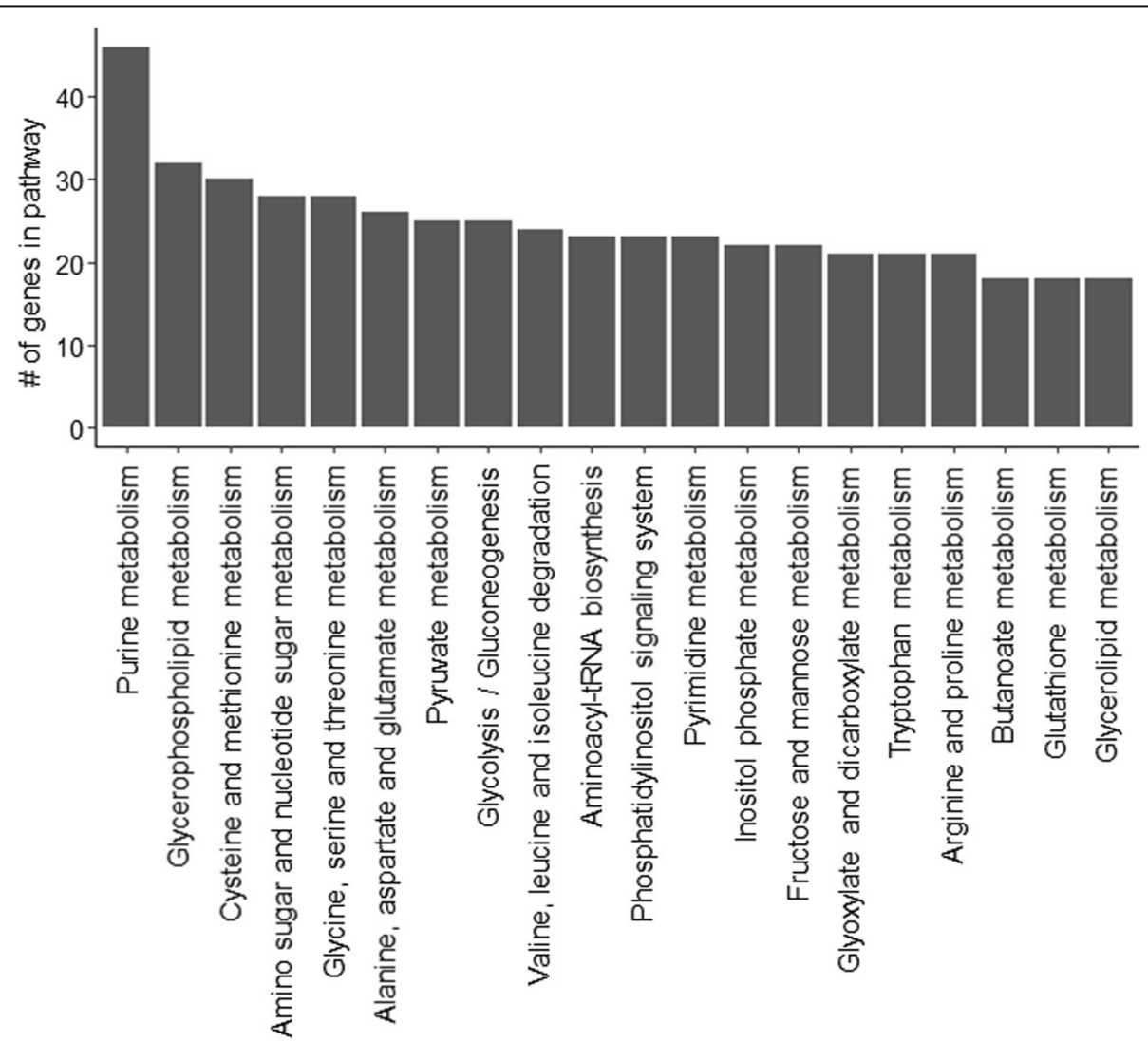

Fig. 3 Most representative KEGG pathways in the whole transcriptome. The KEGG pathways associated with our sequences were loaded using Blast2GO. The $y$-axis shows the number of sequences (or genes) that were annotated in the KEGG pathway. Only the top 20 pathways by number of sequences are shown in the figure. KEGG is developed by Kanehisa Laboratories 

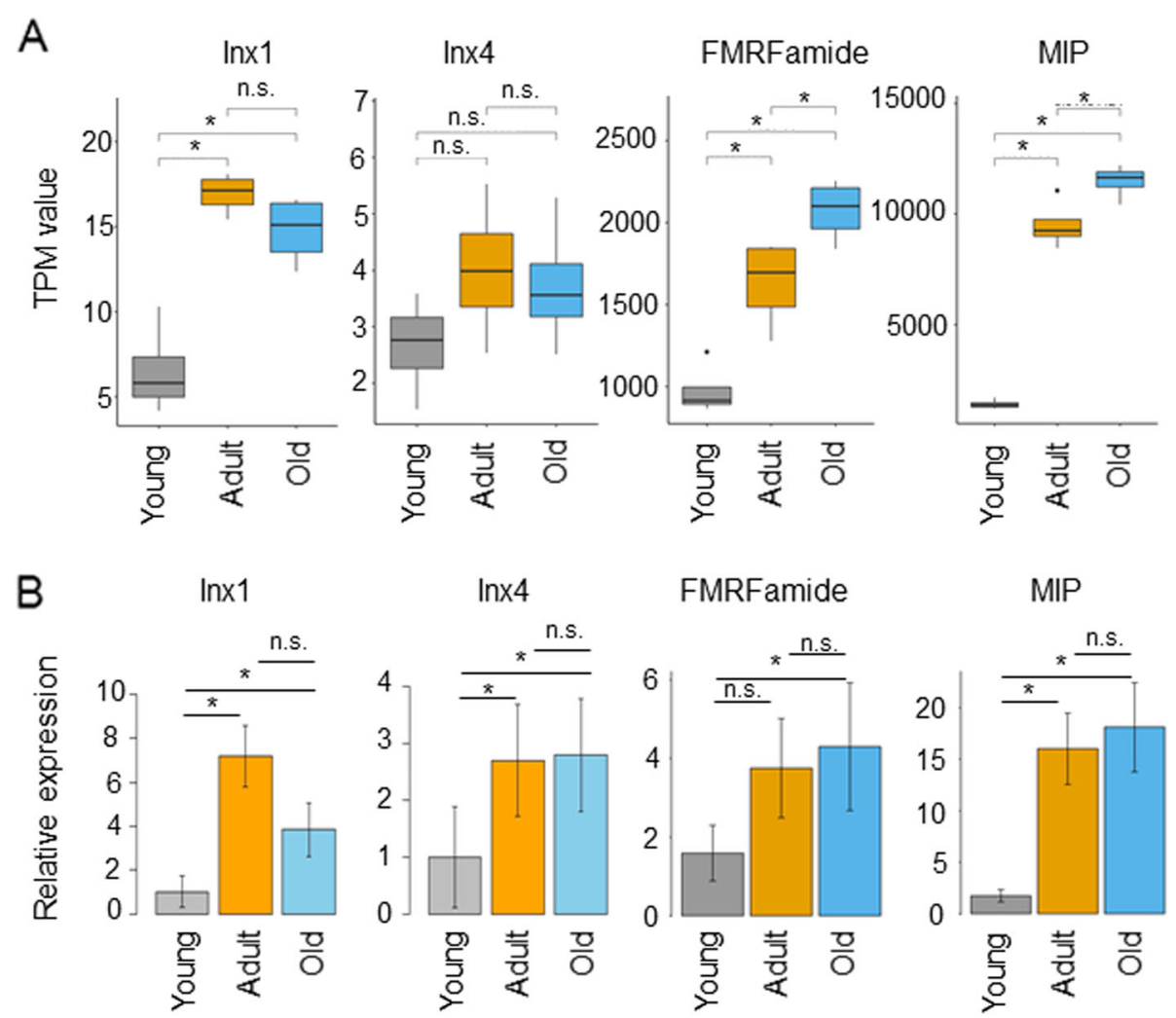

Fig. 4 Confirmation of differential gene expression by real-time qPCR of L. stagnalis genes. A RNA-Seq data reveals gene expression for innexins 1/4, FMRFamide, and molluscan insulin peptide (MIP) in the CNS of young, adult, and old snails. $\mathbf{B}$ real-time qPCR data show patterns of expression comparable to RNA-Seq data. These data show a general concordance of gene expression measured in our transcriptome data compared to qPCR data. ${ }^{*} p<0.05$

MIP and FMRFamide show significant increase in expression from young to adult or old snails (MIP RNASeq FDR adjusted $p$-value young vs adult $p=5.88 \times$ $10^{-86}$, young vs old $p=5.79 \times 10^{-119}$, qPCR Turkey's post-hoc test young vs adult $p=0.00$, young vs old $p=$ 0.00; FMRFamide RNA-Seq FDR adjusted $p$-value young vs adult $p=0.03$, young vs old $p=0.00$; qPCR Turkey's post-hoc test young vs adult $p=0.10$, young vs old $p=$ 0.04). Overall, the concordance between RNA-Seq transcriptome expression and qPCR confirms the reliability of our RNA-Seq measurements.

\section{Quality estimate of transcription assembly: coverage of previously cloned genes}

To further evaluate the quality and completeness of the transcriptome assembly, we tested the coverage of previously cloned genes from L. stagnalis in our transcriptome. According to the most recent NCBI nucleotide database, a total of $242 \mathrm{~L}$. stagnalis genes have been previously cloned (Additional Table 1). There are 210 of these genes $(87 \%)$ present in our transcriptome assembly, supporting that our transcriptome assembly from CNS samples cover most of the previously known protein-coding genes in L. stagnalis. Considering that only a portion of genes are expressed in brain tissues, it is expected that some previously cloned genes would not be detected by this RNA-Seq study.

Among the previously cloned genes mapped in our transcriptome, we can find almost all of the L. stagnalis acetylcholine receptor (LnAChR) subunits. Of the twelve subunits, we found ten in our transcriptome. We further show that in the CNS transcriptome of adult and old snails, the LnAChR subunits $\mathrm{H}$ and $\mathrm{F}$ have the highest expression [58]. Interestingly, in the CNS transcriptome of young snails, subunit $G$ has the highest expression (Fig. 5A). These data seem to suggest changes in LnAChR composition during CNS development. Moreover, two other synaptic receptors, the NMDAR and the serotonin receptor (5-HT receptor) have a significantly lower expression in the young compared to adult and old CNS transcriptomes (NMDAR: RNA-Seq FDR adjusted $p$-value young vs adult $p=$ $6.35 \times 10^{-16}$, young vs old $p=3.08 \mathrm{E}-17$; 5 -HT receptor: RNA-Seq FDR adjusted $p$-value young vs adult $p=$ $9.90 \times 10^{-10}$, young vs old $p=9.41 \times 10^{-5}$ ) (Fig. 5B). Together, these data suggest that our transcriptomes 


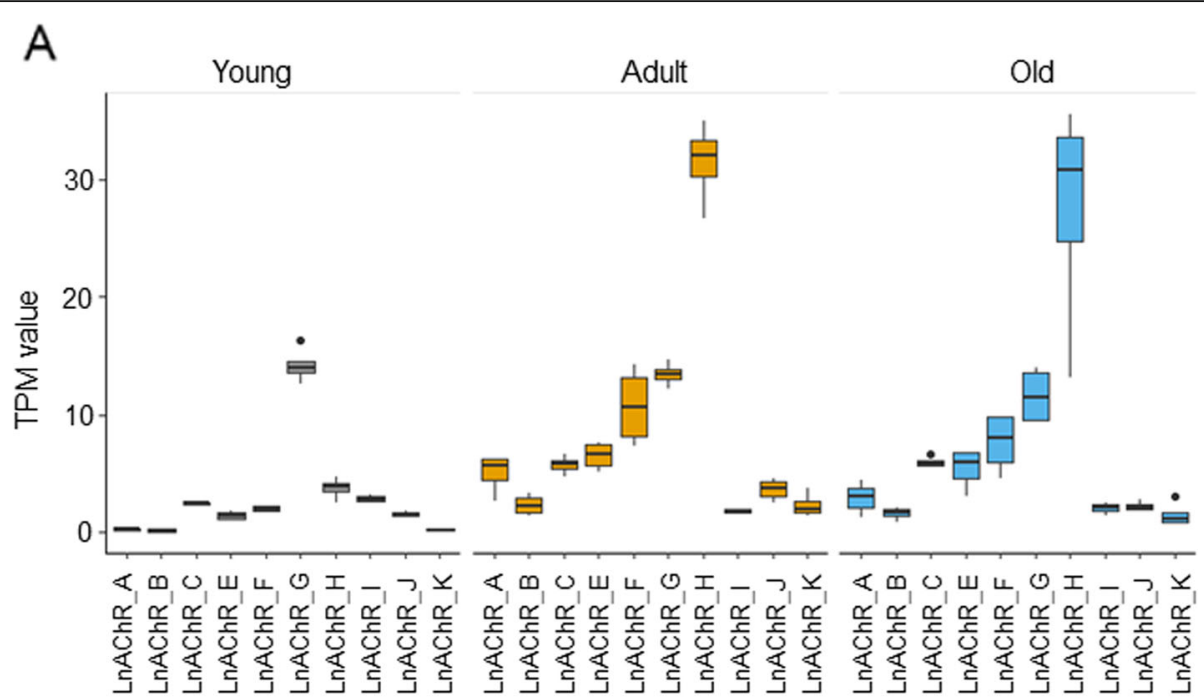

$\mathrm{B}$
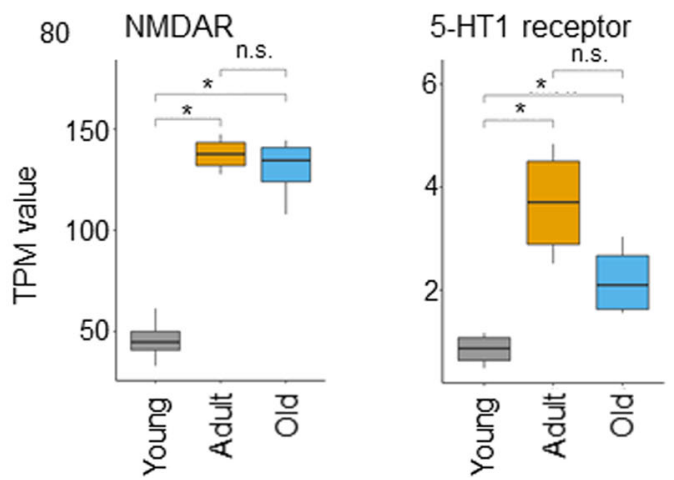

Fig. 5 Differential expression of previously cloned synaptic receptor genes in L. stagnalis. A TPM expression of different L. stagnalis acetylcholine receptor subunits (LnAChR). Consistent with previous literature, the most highly expressed subunit in adult CNS transcriptome is the subunit $\mathrm{H}$. Old snail CNS transcriptome has a similar pattern of LnAChR expression as adult snails. In young snails, though, the most highly expressed subunit is $\mathrm{G}$. These data suggest that acetylcholine receptor subunits are specifically expressed at different life stages. B Genes involved in synaptic transmission (NMDAR, N-Methyl-D-aspartic acid receptor; 5-HT receptor, and serotonin receptor) are significantly downregulated in young snails CNS compared to adult and old. The different patterns of expression for neurotransmitter receptors in young versus adult and old snails suggest that CNS synaptic development requires specific patterning to establish functional synapses throughout the span of $L$. stagnalis life. * $p<0.05$

indeed reveal the expression of many previously cloned genes and their subunits.

\section{Changes in expression of disease-related genes in young,} adult and old animals

Lastly, a recent paper using both A. californica and $L$. stagnalis has provided the cloned sequences for several genes involved in neurodegenerative disorders like Huntington disease, Parkinson's disease (PD), and Alzheimer's disease (AD) [24]. Identification and expression analysis of these genes in the L. stagnalis transcriptome is promising for the use of $L$. stagnalis as a model for studying neurodegenerative diseases. In our transcriptome, we discovered that the expression of these genes changes with age. More specifically, Parkinson's disease protein 7 (PARK7), huntingtin, choline acetyltransferase, and presenilin genes are all upregulated in the CNS of adult and old compared to young animals (Additional Fig. 3).

In addition to these well-recognized genes, there are several other genes that are changed in adult and old animals compared to young animals. These include Arginase 1 (ARG1, linked to many human diseases), reticulons (linked to $\mathrm{AD}$ and amyotrophic lateral sclerosis) [59], proton myo-inositol cotransporter (SCL2A13, linked to AD) [60], Rab GDP dissociation inhibitor (linked to mental retardation) [61], and several tumor genes such as tumor protein D52 (TPD 52), tumor suppressor gene e-cadherin like, and protein phosphatase2A (PP2A); a few of these genes and their expressions in young, adult, and old L. stagnalis are shown in Additional Fig. 3. Expression of these disease-related genes in L. stagnalis provides a unique 
opportunity for using L. stagnalis as a model system to study these genes.

\section{Discussion}

L. stagnalis has served as a unique model organism for the study of neural networks, neuronal development, and synapse formation $[6,14,16]$ due to its simple, wellcharacterized, and easily accessible CNS. In addition, it has recently emerged as a useful model for studying brain aging and neurodegenerative diseases [22-24]. Here, we generated datasets that allow for the first indepth look at transcriptome changes in gene expression of L. stagnalis CNS from young (3 month), adult (6 month), and old (18 month) animals. Our study identifies new $L$. stagnalis sequences, with a good read depth of up to 69 million total fragments ( $150 \mathrm{bp}$ paired-end reads); moreover, we took advantage of the Blast2GO bioinformatics platform to provide gene annotation and gene ontology (GO) annotation for over 30,000 sequences. This study also reveals temporal dynamics of transcriptional profiling and key DE genes/pathways in L. stagnalis CNS at multiple time points of the animal's life span. Such information will be instrumental for future age-related phenotypical analyses in single cells, neuronal networks, and whole animals.

Knowledge about age-associated transcript changes can improve our understanding of how intrinsic profiling plays a role in influencing anatomical, physiological, and pathophysiological properties in animals and human at different life stages. Transcriptomic analyses of human brains at different ages have shown that the majority of protein-coding genes are spatiotemporally regulated, and the transcriptional differences are most pronounced during early development [33]. Similarly, our data reveal that constitutive differences in transcriptomes exist between young and adult CNS, while adult and old CNS exhibit fewer differences in transcripts. In the rat hippocampus, 229 genes were reported to be linearly up- or down-regulated across the lifespan of a healthy animal [35]. Previous studies of transcriptomic profiling of sensory neurons from $A$. californica at 8 (matured), and 12 (aged) months reported that half of the genes were upand half of the genes were down-regulated between the two cohorts of neurons [48]. Our data in this study demonstrates that in L. stagnalis CNS, there are genes exhibiting linear up- or down-regulation from young to adult to old (Fig. 1D), but there are also many genes that are regulated in a non-linear manner. For example, some genes are upregulated from young to adult and appear to either maintain a comparable level of expression or significantly decreased expression in old animals as shown in Figs. 4-5 and Additional Fig. 2-3. The linear or non-linear expression of genes across animals at different ages and in different species may highly correlate with age- and species-specific functions of these genes. Interestingly, the principal component analysis revealed that the majority of L. stagnalis (Additional Fig. 1) biological replicates clustered together. The same clustering pattern was found in A. californica [48] suggesting that individuals of these two species in the same age group share similar transcript profiles. These results suggest that age is an important, determinizing factor for transcriptional profiling between individuals. Together, these data support that whole transcriptome comparison can serve as a valuable tool for discovering age-specific genes, and these mollusc organisms could serve as useful models for studying age-related molecular basics of brain development and aging.

Our analyses indicate that the majority of DE genes occur between young and adult CNS, and the DE genes are enriched in the $\mathrm{GO}$ pathways related to metabolic processes, gene expression, mitochondrial, and ribosome, as well as signalling receptor pathways. Further KEGG analysis revealed significant regulation of pathways for thiamine metabolism and purine metabolism, which regulate energy and nucleotide availability, respectively. These findings are consistent with a recent study of adult $L$. stagnalis CNS transcriptome compared to several other adult organisms used in neurobiology including Mus musculus (mouse), D. rerio (zebrafish), Xenopus tropicalis, C. elegans, and D. melanogaster [31]. Specifically, this study focused on the annotation of the top 20 expressed transcripts in these models. The authors revealed an abundance of transcripts involved in energy production, protein synthesis, and signalling transduction of adult CNS, indicating evolutionally conserved roles of these pathways in mature adult animals of both invertebrates and vertebrates. Because of the importance of these pathways in adult animals, it is not surprising that previous studies have primarily focused on cloning genes involved in these pathways. Indeed, among many cloned genes in our L. stagnalis transcriptome, we can detect $\mathrm{DE}$ genes encoding proteins involved in these pathways. For example, our RNA-Seq data identified ten of the twelve $L$. stagnalis LnAChR subunits that have been previously cloned and sequenced [58]. Interestingly, we provide evidence that these subunits are differentially expressed in the snail's CNS at different ages: the subunit $\mathrm{H}$ is most highly expressed in adult and old, followed by the F subunit, while the G subunit is most highly expressed in young snails. The expression of LnAChR subunits in adult snails is consistent with literature showing that subunits $\mathrm{H}$ and $\mathrm{F}$ together account for approximately half of LnAChR expression in the L. stagnalis CNS as shown by in situ hybridization (ISH) [58]. Studies in rat brain have also shown that various $\mathrm{nAChR}$ subunits are expressed at different ages and in different brain areas [62, 63]. 
Studies comparing primates and humans to rodent brains have shown that the expression of nAChR subunits is conserved in some brain areas but not others [64]. Furthermore, molluscan and other invertebrate species are known to have not only excitatory, sodiumselective nAChRs, but also inhibitory, chloride-selective nAChRs [65]. Considering the properties of cation or anion conductance of LnAChR subunits, we can appreciate the importance of differential expression of these subunits across the lifespan of L. stagnalis for maintaining excitability homeostasis. Specific pharmacological properties have been demonstrated for nAChRs composed of different subunits in both mammalian $[64,66]$, and invertebrate models [67]. Our transcriptome data suggest that the expression pattern or properties of LnAChRs might be important in CNS development and function. Therefore, it would be interesting to investigate the pharmacological properties of the different LnAChR subunits and their spatiotemporal expression and function in the CNS of L. stagnalis in the future.

Among other previously cloned neurotransmitter receptors, we found that the N-Methyl-D-aspartic acid (NMDA) and the serotonin (5-HT) receptors are differentially expressed when comparing the CNS of young and adult/old snails (Fig. 5B). Studies in both human $[68,69]$ and rat $[70]$ have shown differential expression of the NMDAR subunits NR1 and NR2 at different ages. Similarly, 5-HT receptors have been shown to be differentially expressed during human early postnatal development and into adulthood $[68,71]$. Importantly, aberrant expression and/or function of NMDA and 5-HT receptors have been associated with neurodevelopmental disorders such as schizophrenia and autism [72-77]. These changes in neurotransmitter receptor expression at different ages suggest ongoing synaptic development or synaptic diversification when $L$. stagnalis CNS progresses from young to a fully matured stage. The significant up-regulation of genes encoding these transmitter receptors as well as synaptotagmin, gap junctions, ion channels, FMRFamide and MIP (Additional Table 4 and results) clearly indicates the active engagement of intercellular communication and synaptic plasticity in these adult animals. Transcript regulation of synaptic genes may reflect animal behavioural changes; compared to young, adult and old animals normally exhibit more vigorous and diverse behaviours including reproduction, feeding, locomotion, respiration, and associative learning, for which the above-mentioned synaptic machinery components play major roles [5, 17, 31, 78-82].

In addition to previously known genes, it is interesting to note a few unstudied genes in the L. stagnalis transcriptome that exhibit age-specific expression patterns across life stages (as described in results). For example, genes related to oxidative stress and immunity response are either up- or down-regulated in old animals when compared to young and adult animals (Additional Fig. 2). These include cytochrome P450 (CYP2U1 and CYP10), dual oxidase 2 (DUOX2), and suppressor of cytokine signalling 2 (SOCS2). The cytochromes P450 (CYPs) constitute a large superfamily of hemeproteins that are largely involved in the oxidative metabolism of environmental (xenobiotics such as drugs and pesticides) or endogenous (steroid hormones, fatty acid, etc) compounds [83, 84]. Both CYP2U1 transcripts and proteins are widely expressed in various brain regions of human and rats and are involved in the metabolism of fatty acids and xenobiotics in the brain [83]. Interestingly, CYP10 has been cloned in L. stagnalis and found to be abundantly expressed in the female gonadotropic hormone producing dorsal bodies [85]. DUOX are oxidoreductase enzymes that catalyse the synthesis of reactive oxygen species (ROS) molecules including the anion superoxide $\left(\mathrm{O}_{2}{ }^{-}\right)$and hydrogen peroxide $\left(\mathrm{H}_{2} \mathrm{O}_{2}\right)$. DUOX as well as the previously cloned GPX (Supplemental Fig. 2) have recently been demonstrated to be DE in L. stagnalis transcriptome in response to ecoimmunological challenges [86]. SOC2 acts as a negative feedback inhibitor for a variety of cytokine signalling in both vertebrates and invertebrates $[87,88]$. Because of the significant regulation of these oxidative stress and immune defense genes across life stages, it is critical to study their roles in animal health, aging, and diseases in future studies.

Finally, our transcriptomic data also revealed changes in disease-relevant genes associated with neurodegeneration, aging, and cancer, thus affording a unique opportunity to study cellular and molecular functions of these genes by taking advantage of the simplicity of L. stagnalis CNS. In addition, sequenced homologs of several genes known to be involved in aging and neurodegenerative disease (e.g. Parkinson's disease protein 7 (PARK7), huntingtin, presenilin1, and choline acetyltransferase (AChAT) [24], among others) have recently become available. Our data reveals that in L. stagnalis, the expression of these genes is upregulated in adult and old CNS compared to young CNS. In addition to these genes, in the present study, we have discovered several other disease-related genes (Additional Table 5 and Additional Fig. 3). Firstly, the membrane proton myoinositol cotransport (SLC2A13) increases expression in the CNS of adult and old compared to young L. stagnalis. Similar to presenilin1, proton myo-inositol cotransport is found to be a novel gamma-secretase associated protein that selectively regulates $A \beta$ production [60]. Secondly, the present study reveals increased expression of reticulons which have been linked to AD and amyotrophic lateral sclerosis (ALS) [59]. Reticulons is a group of evolutionarily conserved proteins residing predominantly in the endoplasmic reticulum that promote 
membrane curvature, vesicle formation, and nuclear pore complex formation. Since all these proteins are potentially related to $\mathrm{AD}$, it would be interesting to investigate their roles in learning and memory or aging in future studies. While mutation, deletion, or decrease in expression of these disease-related genes are the primary cause of diseases [89-92], the purpose for maintaining a high expression of these gene transcripts in the CNS of adult and old animals is not known. However, our results may partially indicate that the abundant expression of these disease-related genes could be a result of normal physiological requirements or the natural aging process of mollusc CNS.

\section{Conclusions}

Overall, our RNA-seq study provided a much-needed $L$. stagnalis transcriptome assembly, with gene and GO annotation for more than 30,000 predicted genes. Furthermore, the analysis of CNS from different ages demonstrates the importance of this model for uncovering molecular insights in young, adult, and old life stages. This dataset will be useful for future discoveries of genes, expression profiling, and signalling pathways in different ages of animals. It also serves as a helpful resource for future annotation of genes and the genome of L. stagnalis.

\section{Methods}

\section{Animals and brain dissection}

L. stagnalis were maintained in artificial pond water at $20{ }^{\circ} \mathrm{C}$ in a 12 -h light/dark cycle and fed with romaine lettuce twice a week. L. stagnalis were obtained from the University of Calgary, Canada (original stock was from the Vrije University in Amsterdam) and raised and maintained in aquaria at Saint Louis University since 2015 according to protocols developed and optimized as described previously [17, 91]. All procedures are in accordance with the standard operating protocol guidelines established by the U.S. Department of Agriculture Animal and Plant Health Inspection Service. Animals at 3 months old (young), 6 months old (adult) or 18 months old (old) were used for RNA-Seq and qPCR. We used four replicate samples for each developmental age, and for each sample, the CNS of ten animals were pooled. The snails were de-shelled and anesthetized in $10 \%(\mathrm{v} / \mathrm{v})$ Listerine in L. stagnalis saline $(51.3 \mathrm{mM} \mathrm{NaCl} ; 1.7 \mathrm{mM}$ $\mathrm{KCl} ; 4.0 \mathrm{mM} \mathrm{CaCl}$; $1.5 \mathrm{mM} \mathrm{MgCl}_{2}, 10 \mathrm{mM}$ HEPES, pH 7.9), and the dissected central ring ganglia were used for both RNA-Seq and qPCR.

\section{RNA extraction}

RNA was extracted from dissected L. stagnalis central ring ganglia using the RNeasy Mini Kit (Qiagen, 74,104) following the manufacturer's instructions. RNA concentration was assessed using a Nanodrop 2000 Spectrophotometer (ThermoFisher, ND-2000). After RNA extraction, genomic DNA (gDNA) was removed via the TURBO DNA-free kit (Invitrogen, AM1907).

\section{RNA sequencing library construction, sequencing, alignment, and transcriptome assembly}

The construction of RNA-Seq libraries using polyA enrichment method was performed by Novogene Corporation Inc. (Sacramento, CA, USA). These libraries were sequenced using the Illumina NovaSeq 6000 platform (Paired-end, $150 \mathrm{bp}$, insert size $250-300 \mathrm{bp}$ ). The sequencing reads of each RNA-Seq library were aligned to the reference genome of L. stagnalis (assembly v1.0 GCA_900036025.1) using HISAT2 [92]. The soft clipping option in HISAT2 was enabled to exclude lowquality bases at both ends of reads. The number of reads in each sample successfully mapped to the L. stagnalis reference genome are provided in Table 1 . We used Stringtie (93) to assemble transcripts based on aligned reads. The expression abundance of each transcript was quantified as fragment per kilobase million reads (FPKM). To provide between-samples comparability, the data is presented as transcripts per million (TPM) in the figures. The results of principal component analyses (PCA) of the abundance of transcripts (FPKM) for all genes from all samples are provided in Additional Fig. 1A. The correlations of gene expression profile between each pair of samples are provided in Additional Fig. 1B. The raw sequencing data generated in this study have been submitted to the NCBI BioProject database under accession number PRJNA698985.

\section{Functional annotation of inferred $L$. stagnalis genes}

We first used TransDecoder v5.5.0 (94) to retrieve CDS and amino acid sequences for each assembled transcript from the L. stagnalis reference genome based on the merged annotation file generated by Stringtie. We applied two different methods to annotate inferred L. stagnalis genes and combined the annotated information. The first method was based on BLASTP searches against NCBI RefSeq amino acid sequences of nine species closely related to L. stagnalis. These species included: Biomphalaria glabrata, Aplysia californica,, Lottia gigantea, Pomacea canaliculata, Octopus bimaculoides, Octopus vulgaris, Crassostrea virginica, Crassostrea gigas, and Mizuhopecten yessoensis. The second method was to search for the presence of Pfam domains in the inferred L. stagnalis amino acid sequences using the "hmmscan" tool in HMMER3 (95). The BLASTP and Pfam search results were integrated into the annotation of predicted L. stagnalis open reading frames (ORFs) using TransDecoder-v5.5.0 (94). 
Gene ontology and KEGG annotation of inferred genes in L. stagnalis

We used predicted protein sequences of $L$. stagnalis with at least 100 amino acids for both Gene Ontology (GO) and KEGG [52-54] annotation using Blast2GO [50]. This annotation analysis was based on homology searches against the Mollusca phylum, C. elegans, D. melanogaster, and $H$. sapiens using the latest reference protein database (refseq_protein v5). We used an e-value threshold of 1.0E-3, top 20 blast hits, word size 6 , and HSP length cut-off of 33. GO annotation was based on the latest GO version (2020.06). For both GO and KEGG enrichment analysis, Fisher's exact test was used in combination with a False Discovery Rate (FDR) correction for multiple testing (FDR $<0.05$ ). $\mathrm{R}$ (96) package ggplot2 was used to plot results of both enrichment analyses.

\section{Identification of previously cloned genes in L. stagnalis}

We searched for previously cloned genes in L. stagnalis from the NCBI nucleotide database (as of January 2021) to evaluate the completeness of our transcriptome assembly. Only cloned genes that were supported by published studies were selected. The list of previously cloned genes in L. stagnalis (NCBI ID, gene names and references) is provided in Additional Table 1.

\section{Differential gene expression analysis and validation of gene expression by real-time qPCR}

Differential expression (DE) analysis was carried out using DESeq2 (97) based on raw read counts retrieved by the featureCounts package of Subread v1.5.0 (98). The results of DE analysis by DESeq2 are shown in Additional file 1.

We validated the differential gene expression through real-time quantitative polymerase chain reactions (RTqPCR). cDNA synthesis was performed from gDNAremoved RNA samples using SuperScript IV VILO Master Mix (Invitrogen, 11,766,050) following the manufacturer's instructions. SYBR Green PCR Master Mix (Applied Biosystems, 4,309,155) was used for RT-qPCR in a QuantStudio 5 Real-Time PCR System (ThermoFisher). Primers are listed in Additional Table 2. Primer set efficiency values ranged from $95.85-104.26 \%$, and $\mathrm{R}^{2}$ values were $0.98-0.99$. Two negative controls were used: qPCR without reverse transcription and no template controls. Relative gene expression was normalized to reference gene $\beta$-tubulin. The final qPCR product was also sequenced to ensure the correct innexin paralog was amplified.

Because of the wide range of primer efficiencies, relative gene expression was calculated via the Common Base Method (99) and normalized to reference gene $\beta$ tubulin. Analysis of variance (ANOVA) was used to determine statistically significant differences in gene expression at $p<0.05$, and Tukey's HSD Post-hoc test was used when appropriate.

\section{Abbreviations}

CDS: Coding sequences; CNS: Central nervous system; EST: Expressed sequence tags; DE: Differentially expressed; GO: Gene ontology; FPKM: Fragment per kilobase million; TPM: Transcripts per milion; NMDA: Nmethyl-D-aspartate receptor; CYP: Cytochrome P450; CDO1: Cysteine dioxygenase 1; ECM: Extracellular matrix; DUOX2: Dual oxydase 2;

SOCS2: Suppressor of cytokine signaling 2; HSP60: Heat-shock protein 60; LnAChR: L. stagnalis acetylcholine receptor; 5-HT: Serotonin; MIP: Molluscan insulin peptide; AQP1: Aquaporin1; TPH: Tryptophan hydroxylase;

GPX: Glutathione peroxidase; PD: Parkinson's disease; AD: Alzheimer's disease; PARK7: Parkinson's disease protein 7; ChAT: Choline acetyltransferase; ARG-

1: Arginase 1; SCL2A13: Membrane proton myo-inositol cotransporter;

PP2A: Protein phosphatase 2A

\section{Supplementary Information}

The online version contains supplementary material available at https://doi. org/10.1186/s12864-021-07946-y.

Additional file 1.

Additional file 2.

Additional file 3.

Additional file 4

Additional file 5 .

Additional file 6.

Additional file 7.

Additional file 8.

Additional file 9.

Additional file 10.

Acknowledgements

Not applicable.

Authors' contributions

$\mathrm{MR}, \mathrm{BH}, \mathrm{ZL}$, and FX participated in the study design. FX carried out the dissection of brains and $\mathrm{BH}$ performed RNA extraction and $\mathrm{PPCR}$. ZL provided the RNA-Seq library, sequencing alignment and transcriptome assembly. MR performed GO annotation and pathway enrichment. CA organized the data for Table 1 and Fig. 4. MR and FX drafted the manuscript. All authors read, edited and approved the final manuscript.

Funding

This work was supported by the National Science Foundation (1916563) and the Saint Louis University Start-up Fund awarded to Dr. Xu.

Availability of data and materials

All raw RNA-seq reads are archived under NCBI BioProject \# PRJNA698985 (https://www.ncbi.n/m.nih.gov/bioproject/?term=PRJNA698985). Previously cloned gene list and $\mathrm{NCBI}$ accession numbers are provided in Additional Table 2. Annotation and transcript sequences information are provided in Additional files 1 and 2 .

\section{Declarations}

Ethics approval and consent to participate

The study was carried out in compliance with the Animal Research: Reporting of In Vivo Experiments (ARRIVE) guidelines. Animals were anesthetized and dissected in accordance with the standard operating protocol guidelines established by the United States Department of Agriculture (USDA) Animal and Plant Health Inspections Service (animal permit \#: P526P-19-01621). All experiments were performed according to the guidelines of the Institutional Biosafety Committee and Animal Care Committee of Saint Louis University. Procedures of snail research in the standard Laboratory Biosafety Protocol were also approved by Saint Louis University. 


\section{Consent for publication}

Not applicable.

\section{Competing interests}

The authors declare no competing and financial interests.

\section{Author details}

${ }^{1}$ Department of Biology, College of Arts and Sciences, Saint Louis University, St. Louis, MO, USA. ${ }^{2}$ Henry and Amelia Nasrallah Center for Neuroscience, Saint Louis University, St. Louis, MO, USA. ${ }^{3}$ Department of Pharmacology and Physiology, Saint Louis University, School of Medicine, St. Louis, MO, USA.

Received: 20 May 2021 Accepted: 23 August 2021

Published online: 03 September 2021

\section{References}

1. Kuroda R, Abe M. The pond snail Lymnaea stagnalis. Evodevo. 2020;11(1):24. https://doi.org/10.1186/s13227-020-00169-4.

2. Fodor I, Hussein AA, Benjamin PR, Koene JM, Pirger Z. The unlimited potential of the great pond snail, Lymnaea stagnalis. Elife. 2020;9:e56962

3. Mersman B, Zaidi W, Syed NI, Xu F. Taurine promotes neurite outgrowth and synapse development of both vertebrate and invertebrate central neurons. Front Synaptic Neurosci. 2020;12:29. https://doi.org/10.3389/fnsyn.2 020.00029.

4. Kojima S, Nanakamura H, Nagayama S, Fujito Y, Ito E. Enhancement of an inhibitory input to the feeding central pattern generator in Lymnaea stagnalis during conditioned taste-aversion learning. Neurosci Lett. 1997; 230(3):179-82. https://doi.org/10.1016/S0304-3940(97)00507-7.

5. Yeoman MS, Kemenes G, Benjamin PR, Elliott CJ. Modulatory role for the serotonergic cerebral giant cells in the feeding system of the snail, Lymnaea II Photoinactivation. J Neurophysiol. 1994;72(3):1372-82. https://doi.org/1 0.1152/jn.1994.72.3.1372.

6. Haque Z, Lee TK, Inoue T, Luk C, Hasan SU, Lukowiak K, et al. An identified central pattern-generating neuron co-ordinates sensory-motor components of respiratory behavior in Lymnaea. Eur J Neurosci. 2006;23(1):94-104. https://doi.org/10.1111/j.1460-9568.2005.04543.x.

7. Taylor BE, Lukowiak K. The respiratory central pattern generator of Lymnaea: a model, measured and malleable. Respir Physiol. 2000;122(2-3):197-207. https://doi.org/10.1016/S0034-5687(00)00159-6.

8. Syed NI, Winlow W. Coordination of locomotor and cardiorespiratory networks of Lymnaea stagnalis by a pair of identified interneurones. J Exp Biol. 1991;158(1):37-62. https://doi.org/10.1242/jeb.158.1.37.

9. Vorontsov DD, Tsyganov W, Sakharov DA. Phasic coordination between locomotor and respiratory rhythms in Lymnaea. Real behavior and computer simulation. Acta Biol Hung. 2004;55(1-4):233-7. https://doi.org/1 0.1556/ABiol.55.2004.1-4.28

10. Hermann PM, de Lange RP, Pieneman AW, ter Maat A, Jansen RF. Role of neuropeptides encoded on $\mathrm{CDCH}-1$ gene in the organization of egg-laying behavior in the pond snail, Lymnaea stagnalis. J Neurophysiol. 1997;78(6): 2859-69. https://doi.org/10.1152/jn.1997.78.6.2859.

11. Jimenez CR, ter Maat A, Pieneman A, Burlingame AL, Smit AB, Li KW. Spatiotemporal dynamics of the egg-laying-inducing peptides during an egglaying cycle: a semiquantitative matrix-assisted laser desorption/ionization mass spectrometry approach. J Neurochem. 2004;89(4):865-75. https://doi. org/10.1111/j.1471-4159.2004.02353.x.

12. Dodd S, Rothwell CM, Lukowiak K. Strain-specific effects of crowding on long-term memory formation in Lymnaea. Comp Biochem Physiol A Mol Integr Physiol. 2018;222:43-51. https://doi.org/10.1016/j.cbpa.2018.04.010.

13. Sunada H, Watanabe T, Hatakeyama D, Lee S, Forest J, Sakakibara M, et al. Pharmacological effects of cannabinoids on learning and memory in Lymnaea. J Exp Biol. 2017;220(Pt 17):3026-38. https://doi.org/10.1242/jeb.1 59038.

14. Swinton C, Swinton E, Shymansky T, Hughes E, Zhang J, Rothwell C, et al. Configural learning: a higher form of learning in Lymnaea. J Exp Biol. 2019; 222(Pt 3):jeb190405.

15. Tan R, Lukowiak K. Combining factors that individually enhance memory in Lymnaea. Biol Bull. 2018;234(1):37-44. https://doi.org/10.1086/697197.

16. Getz AM, Wijdenes P, Riaz S, Syed NI. Uncovering the cellular and molecular mechanisms of synapse formation and functional specificity using central neurons of Lymnaea stagnalis. ACS Chem Neurosci. 2018;9(8):1928-38. https://doi.org/10.1021/acschemneuro.7b00448.
17. Mersman BA, Jolly SN, Lin Z, Xu F. Gap junction coding Innexin in Lymnaea stagnalis: sequence analysis and characterization in tissues and the central nervous system. Front Synaptic Neurosci. 2020;12:1. https://doi.org/10.3389/ fnsyn.2020.00001.

18. Onizuka S, Shiraishi S, Tamura R, Yonaha T, Oda N, Kawasaki Y, et al. Lidocaine treatment during synapse reformation periods permanently inhibits NGF-induced excitation in an identified reconstructed synapse of Lymnaea stagnalis. J Anesth. 2012;26(1):45-53. https://doi.org/10.1007/s0054 0-011-1257-6.

19. Arundell M, Patel BA, Straub V, Allen MC, Janse C, O'Hare D, et al. Effects of age on feeding behavior and chemosensory processing in the pond snail, Lymnaea stagnalis. Neurobiol Aging. 2006;27(12):1880-91. https://doi.org/1 0.1016/j.neurobiolaging.2005.09.040.

20. de Weerd L, Hermann PM, Wildering WC. Linking the 'why' and 'how' of ageing: evidence for somatotropic control of long-term memory function in the pond snail Lymnaea stagnalis. J Exp Biol. 2017;220(Pt 22):4088-94. https://doi.org/10.1242/jeb.167395.

21. Ford L, Crossley M, Vadukul DM, Kemenes G, Serpell LC. Structure-dependent effects of amyloid-beta on long-term memory in Lymnaea stagnalis. FEBS Lett. 2017;591(9):1236-46. https://doi.org/10.1002/1873-3468.12633.

22. Hermann PM, Perry AC, Hamad I, Wildering WC. Physiological and pharmacological characterization of a molluscan neuronal efflux transporter; evidence for age-related transporter impairment. J Exp Biol. 2020;223(Pt 2): jeb213785.

23. Maasz G, Zrinyi Z, Reglodi D, Petrovics D, Rivnyak A, Kiss T, et al. Pituitary adenylate cyclase-activating polypeptide (PACAP) has a neuroprotective function in dopamine-based neurodegeneration in rat and snail parkinsonian models. Dis Model Mech. 2017;10(2):127-39. https://doi.org/1 0.1242/dmm.027185.

24. Fodor I, Urban P, Kemenes G, Koene JM, Pirger Z. Aging and diseaserelevant gene products in the neuronal transcriptome of the great pond snail (Lymnaea stagnalis): a potential model of aging, age-related memory loss, and neurodegenerative diseases. Invertebr Neurosci. 2020;20(3):9. https://doi.org/10.1007/s10158-020-00242-6.

25. Moroz LL, Edwards JR, Puthanveettil SV, Kohn AB, Ha T, Heyland A, et al. Neuronal transcriptome of Aplysia: neuronal compartments and circuitry. Cell. 2006;127(7):1453-67. https://doi.org/10.1016/j.cell.2006.09.052.

26. Moroz LL, Kohn AB. Do different neurons age differently? Direct genomewide analysis of aging in single identified cholinergic neurons. Front Aging Neurosci. 2010;2:6

27. Abe M, Kuroda R. The development of CRISPR for a mollusc establishes the formin Lsdia1 as the long-sought gene for snail dextral/sinistral coiling. Development. 2019;146(9):dev175976.

28. Bouetard A, Noirot C, Besnard AL, Bouchez O, Choisne D, Robe E, et al. Pyrosequencing-based transcriptomic resources in the pond snail Lymnaea stagnalis, with a focus on genes involved in molecular response to diquatinduced stress. Ecotoxicology. 2012;21(8):2222-34. https://doi.org/10.1007/s1 0646-012-0977-1.

29. Davison A, Blaxter ML. An expressed sequence tag survey of gene expression in the pond snail Lymnaea stagnalis, an intermediate vector of trematodes [corrected]. Parasitology. 2005;130(Pt 5):539-52. https://doi.org/1 $0.1017 /$ S0031182004006791.

30. Feng ZP, Zhang Z, van Kesteren RE, Straub VA, van Nierop $P$, Jin $K$, et al. Transcriptome analysis of the central nervous system of the mollusc Lymnaea stagnalis. BMC Genomics. 2009;10(1):451. https://doi.org/10.1186/1471-2164-10-451.

31. Dong N, Bandura J, Zhang Z, Wang Y, Labadie K, Noel B, et al. lon channel profiling of the Lymnaea stagnalis ganglia via transcriptome analysis. BMC Genomics. 2021;22(1):18. https://doi.org/10.1186/s12864-020-07287-2.

32. Sadamoto H, Takahashi H, Okada T, Kenmoku H, Toyota M, Asakawa Y. De novo sequencing and transcriptome analysis of the central nervous system of mollusc Lymnaea stagnalis by deep RNA sequencing. PLoS One. 2012; 7(8):e42546. https://doi.org/10.1371/journal.pone.0042546.

33. Kang HJ, Kawasawa Yl, Cheng F, Zhu Y, Xu X, Li M, et al. Spatio-temporal transcriptome of the human brain. Nature. 2011;478(7370):483-9. https://doi. org/10.1038/nature10523.

34. Tebbenkamp AT, Willsey AJ, State MW, Sestan N. The developmental transcriptome of the human brain: implications for neurodevelopmental disorders. Curr Opin Neurol. 2014;27(2):149-56. https://doi.org/10.1097/WCO. 0000000000000069 .

35. Shavlakadze T, Morris M, Fang J, Wang SX, Zhu J, Zhou W, et al. Age-related gene expression signature in rats demonstrate early, late, and linear 
transcriptional changes from multiple tissues. Cell Rep. 2019;28(12):3263-73 e3. https://doi.org/10.1016/j.celrep.2019.08.043.

36. Chou SJ, Wang C, Sintupisut N, Niou ZX, Lin CH, Li KC, et al. Analysis of spatial-temporal gene expression patterns reveals dynamics and regionalization in developing mouse brain. Sci Rep. 2016;6(1):19274. https:// doi.org/10.1038/srep19274

37. Xu Z, Che T, Li F, Tian K, Zhu Q, Mishra SK, et al. The temporal expression patterns of brain transcriptome during chicken development and ageing. BMC Genomics. 2018;19(1):917. https://doi.org/10.1186/s12864-018-5301-X.

38. Vesterlund $L$, Jiao $H$, Unneberg $P$, Hovatta $O$, Kere J. The zebrafish transcriptome during early development. BMC Dev Biol. 2011;11(1):30. https://doi.org/10.1186/1471-213X-11-30.

39. Frias-Soler RC, Pildain LV, Parau LG, Wink M, Bairlein F. Transcriptome signatures in the brain of a migratory songbird. Comp Biochem Physiol Part D Genomics Proteomics. 2020;34:100681. https://doi.org/10.1016/j.cbd.202 0.100681 .

40. Boeck ME, Huynh C, Gevirtzman L, Thompson OA, Wang G, Kasper DM, et al. The time-resolved transcriptome of C. elegans. Genome Res. 2016; 26(10):1441-50. https://doi.org/10.1101/gr.202663.115.

41. Lu MR, Lai CK, Liao BY, Tsai IJ. Comparative transcriptomics across nematode life cycles reveal gene expression conservation and correlated evolution in adjacent developmental stages. Genome Biol Evol. 2020;12(7): 1019-30. https://doi.org/10.1093/gbe/evaa110.

42. Graveley BR, Brooks AN, Carlson JW, Duff MO, Landolin JM, Yang L, et al. The developmental transcriptome of Drosophila melanogaster. Nature. 2011;471(7339):473-9. https://doi.org/10.1038/nature09715.

43. Moskalev AA, Shaposhnikov MV, Zemskaya NV, Koval Lcapital AC, Schegoleva EV, Guvatova ZG, et al. Transcriptome analysis of long-lived Drosophila melanogaster $\mathrm{E}(\mathrm{z})$ mutants sheds light on the molecular mechanisms of longevity. Sci Rep. 2019;9(1):9151. https://doi.org/10.1038/ s41598-019-45714-X.

44. Pacifico R, MacMullen CM, Walkinshaw E, Zhang X, Davis RL. Brain transcriptome changes in the aging Drosophila melanogaster accompany olfactory memory performance deficits. PLoS One. 2018;13(12):e0209405. https://doi.org/10.1371/journal.pone.0209405.

45. Tarkhov AE, Alla R, Ayyadevara S, Pyatnitskiy M, Menshikov LI, Shmookler Reis RJ, et al. A universal transcriptomic signature of age reveals the temporal scaling of Caenorhabditis elegans aging trajectories. Sci Rep. 2019; 9(1):7368. https://doi.org/10.1038/s41598-019-43075-z.

46. Heyland A, Vue Z, Voolstra CR, Medina M, Moroz LL. Developmental transcriptome of Aplysia californica. J Exp Zool B Mol Dev Evol. 2011; 316B(2):113-34. https://doi.org/10.1002/jez.b.21383.

47. Liu MM, Davey JW, Jackson DJ, Blaxter ML, Davison A. A conserved set of maternal genes? Insights from a molluscan transcriptome. Int J Dev Biol. 2014;58(6-8):501-11. https://doi.org/10.1387/ijdb.140121ad.

48. Greer JB, Schmale MC, Fieber LA. Whole-transcriptome changes in gene expression accompany aging of sensory neurons in Aplysia californica. BMC Genomics. 2018;19(1):529. https://doi.org/10.1186/s12864-018-4909-1.

49. Hermann PM, Lee A, Hulliger S, Minvielle M, Ma B, Wildering WC. Impairment of long-term associative memory in aging snails (Lymnaea stagnalis). Behav Neurosci. 2007;121(6):1400-14. https://doi.org/10.1037/073 5-7044.121.6.1400.

50. Janse C, Slob W, Popelier CM, Vogelaar JW. Survival characteristics of the mollusc Lymnaea stagnalis under constant culture conditions: effects of aging and disease. Mech Ageing Dev. 1988;42(3):263-74. https://doi.org/10.1 016/0047-6374(88)90052-8.

51. Conesa A, Gotz S, Garcia-Gomez JM, Terol J, Talon M, Robles M. Blast2GO: a universal tool for annotation, visualization and analysis in functional genomics research. Bioinformatics. 2005;21(18):3674-6. https://doi.org/10.1 093/bioinformatics/bti610.

52. Kanehisa M, Goto S. KEGG: Kyoto encyclopedia of genes and genomes. Nucleic Acids Res. 2000;28(1):27-30. https://doi.org/10.1093/nar/28.1.27.

53. Kanehisa M. Toward understanding the origin and evolution of cellular organisms. Protein Sci. 2019;28(11):1947-51. https://doi.org/10.1002/pro.3715.

54. Kanehisa M, Furumichi M, Sato Y, Ishiguro-Watanabe M, Tanabe M. KEGG: integrating viruses and cellular organisms. Nucleic Acids Res. 2021;49(D1): D545-D51. https://doi.org/10.1093/nar/gkaa970.

55. Kellett E, Saunders SE, Li KW, Staddon JW, Benjamin PR, Burke JF. Genomic organization of the FMRFamide gene in Lymnaea: multiple exons encoding novel neuropeptides. J Neurosci. 1994;14(11 Pt 1):6564-70. https://doi.org/1 0.1523/JNEUROSCI.14-11-06564.1994.
56. Linacre A, Kellett E, Saunders S, Bright K, Benjamin PR, Burke JF. Cardioactive neuropeptide Phe-met-Arg-Phe-NH2 (FMRFamide) and novel related peptides are encoded in multiple copies by a single gene in the snail Lymnaea stagnalis. J Neurosci. 1990;10(2):412-9. https://doi.org/10.1523/ JNEUROSCI.10-02-00412.1990.

57. Smit AB, Vreugdenhil E, Ebberink RH, Geraerts WP, Klootwijk J, Joosse J. Growthcontrolling molluscan neurons produce the precursor of an insulin-related peptide. Nature. 1988;331(6156):535-8. https://doi.org/10.1038/331535a0.

58. van Nierop P, Bertrand S, Munno DW, Gouwenberg Y, van Minnen J, Spafford JD, et al. Identification and functional expression of a family of nicotinic acetylcholine receptor subunits in the central nervous system of the mollusc Lymnaea stagnalis. J Biol Chem. 2006;281(3):1680-91. https:// doi.org/10.1074/jbc.M508571200.

59. Yang YS, Strittmatter SM. The reticulons: a family of proteins with diverse functions. Genome Biol. 2007;8(12):234. https://doi.org/10.1186/gb-20078-12-234.

60. Teranishi Y, Inoue M, Yamamoto NG, Kihara T, Wiehager B, Ishikawa T, et al. Proton myo-inositol cotransporter is a novel gamma-secretase associated protein that regulates Abeta production without affecting notch cleavage. FEBS J. 2015;282(17):3438-51. https://doi.org/10.1111/febs.13353.

61. Ishizaki H, Miyoshi J, Kamiya H, Togawa A, Tanaka M, Sasaki T, et al. Role of Rab GDP dissociation inhibitor alpha in regulating plasticity of hippocampal neurotransmission. Proc Natl Acad Sci U S A. 2000;97(21):11587-92. https:// doi.org/10.1073/pnas.97.21.11587.

62. Cimino M, Marini P, Colombo S, Andena M, Cattabeni F, Fornasari D, et al. Expression of neuronal acetylcholine nicotinic receptor alpha 4 and beta 2 subunits during postnatal development of the rat brain. J Neural Transm Gen Sect. 1995;100(2):77-92. https://doi.org/10.1007/BF01271531.

63. Zhang X, Liu C, Miao H, Gong ZH, Nordberg A. Postnatal changes of nicotinic acetylcholine receptor alpha 2, alpha 3, alpha 4, alpha 7 and beta 2 subunits genes expression in rat brain. Int J Dev Neurosci. 1998;16(6):50718. https://doi.org/10.1016/S0736-5748(98)00044-6.

64. Zoli M, Pistillo F, Gotti C. Diversity of native nicotinic receptor subtypes in mammalian brain. Neuropharmacology. 2015;96(Pt B):302-11.

65. van Nierop P, Keramidas A, Bertrand S, van Minnen J, Gouwenberg Y, Bertrand $D$, et al. Identification of molluscan nicotinic acetylcholine receptor (nAChR) subunits involved in formation of cation- and anion-selective nAChRs. J Neurosci. 2005;25(46):10617-26. https://doi.org/10.1523/ JNEUROSCI.2015-05.2005.

66. Papke RL, Dwoskin LP, Crooks PA. The pharmacological activity of nicotine and nornicotine on nAChRs subtypes: relevance to nicotine dependence and drug discovery. J Neurochem. 2007;101(1):160-7. https://doi.org/1 $0.1111 /$ j.1471-4159.2006.04355.x.

67. Lansdell SJ, Collins T, Goodchild J, Millar NS. The Drosophila nicotinic acetylcholine receptor subunits Dalpha5 and Dalpha7 form functional homomeric and heteromeric ion channels. BMC Neurosci. 2012;13(1):73. https://doi.org/10.1186/1471-2202-13-73.

68. Bar-Shira O, Maor R, Chechik G. Gene expression switching of receptor subunits in human brain development. PLoS Comput Biol. 2015;11(12): e1004559. https://doi.org/10.1371/journal.pcbi.1004559.

69. Law AJ, Weickert CS, Webster MJ, Herman MM, Kleinman JE, Harrison PJ. Expression of NMDA receptor NR1, NR2A and NR2B subunit mRNAs during development of the human hippocampal formation. Eur J Neurosci. 2003; 18(5):1197-205. https://doi.org/10.1046/j.1460-9568.2003.02850.x.

70. Monyer H, Burnashev N, Laurie DJ, Sakmann B, Seeburg PH. Developmental and regional expression in the rat brain and functional properties of four NMDA receptors. Neuron. 1994;12(3):529-40. https://doi.org/10.1016/08966273(94)90210-0.

71. Lambe EK, Fillman SG, Webster MJ, Shannon WC. Serotonin receptor expression in human prefrontal cortex: balancing excitation and inhibition across postnatal development. PLoS One. 2011;6(7):e22799. https://doi.org/1 0.1371/journal.pone.0022799.

72. Carlsson ML. Hypothesis: is infantile autism a hypoglutamatergic disorder? Relevance of glutamate - serotonin interactions for pharmacotherapy. J Neural Transm (Vienna). 1998;105(4-5):525-35. https://doi.org/10.1007/s007020050076.

73. du Bois TM, Huang XF. Early brain development disruption from NMDA receptor hypofunction: relevance to schizophrenia. Brain Res Rev. 2007;53(2): 260-70. https://doi.org/10.1016/j.brainresrev.2006.09.001.

74. Ju P, Cui D. The involvement of N-methyl-D-aspartate receptor (NMDAR) subunit NR1 in the pathophysiology of schizophrenia. Acta Biochim Biophys Sin Shanghai. 2016;48(3):209-19. https://doi.org/10.1093/abbs/gmv135. 
75. Seshadri S, Klaus A, Winkowski DE, Kanold PO, Plenz D. Altered avalanche dynamics in a developmental NMDAR hypofunction model of cognitive impairment. Transl Psychiatry. 2018;8(1):3. https://doi.org/10.1038/541398-017-0060-z.

76. Sodhi MS, Sanders-Bush E. Serotonin and brain development. Int Rev Neurobiol. 2004;59:111-74. https://doi.org/10.1016/50074-7742(04)59006-2.

77. Xia X, Ding M, Xuan JF, Xing JX, Pang H, Wang BJ, et al. Polymorphisms in the human serotonin receptor $1 \mathrm{~B}$ (HTR1B) gene are associated with schizophrenia: a case control study. BMC Psychiatry. 2018;18(1):303. https:/ doi.org/10.1186/s12888-018-1849-x.

78. Ha TJ, Kohn AB, Bobkova YV, Moroz LL. Molecular characterization of NMDA-like receptors in Aplysia and Lymnaea: relevance to memory mechanisms. Biol Bull. 2006;210(3):255-70. https://doi.org/10.2307/4134562.

79. Hoek RM, Li KW, van Minnen J, Lodder JC, de Jong-Brink M, Smit AB, et al. LFRFamides: a novel family of parasitation-induced -RFamide neuropeptides that inhibit the activity of neuroendocrine cells in Lymnaea stagnalis. J Neurochem. 2005;92(5):1073-80. https://doi.org/10.1111/j.1471-4159.2004.02 927.x.

80. Ito E, Okada R, Sakamoto Y, Otshuka E, Mita K, Okuta A, et al. Insulin and memory in Lymnaea. Acta Biol Hung. 2012;63(Suppl 2):194-201. https://doi. org/10.1556/ABiol.63.2012.Suppl.2.25.

81. Kojima S, Sunada H, Mita K, Sakakibara M, Lukowiak K, Ito E. Function of insulin in snail brain in associative learning. J Comp Physiol A Neuroethol Sens Neural Behav Physiol. 2015;201(10):969-81. https://doi.org/10.1007/ s00359-015-1032-5.

82. Murakami J, Okada R, Sadamoto H, Kobayashi S, Mita K, Sakamoto Y, et al. Involvement of insulin-like peptide in long-term synaptic plasticity and long-term memory of the pond snail Lymnaea stagnalis. J Neurosci. 2013; 33(1):371-83. https://doi.org/10.1523/JNEUROSCI.0679-12.2013.

83. Dhers L, Ducassou L, Boucher JL, Mansuy D. Cytochrome P450 2U1, a very peculiar member of the human P450s family. Cell Mol Life Sci. 2017;74(10): 1859-69. https://doi.org/10.1007/s00018-016-2443-3.

84. Montellano O. Cytochrome P450: structure, mechanism and biochemistry. 4th ed. New York: Kluwer Academic/Plenum Publishers; 2015.

85. Teunissen Y, Geraerts WP, van Heerikhuizen H, Planta RJ, Joosse J. Molecular cloning of a cDNA encoding a member of a novel cytochrome P450 family in the mollusc Lymnaea stagnalis. J Biochem. 1992;112(2):249-52. https:// doi.org/10.1093/oxfordjournals.jbchem.a123885.

86. Seppala O, Walser JC, Cereghetti T, Seppala K, Salo T, Adema CM. Transcriptome profiling of Lymnaea stagnalis (Gastropoda) for ecoimmunological research. BMC Genomics. 2021;22(1):144. https://doi. org/10.1186/s12864-021-07428-1.

87. Wang B, Wangkahart E, Secombes CJ, Wang T. Insights into the evolution of the suppressors of cytokine signaling (SOCS) gene family in vertebrates. Mol Biol Evol. 2019;36(2):393-411. https://doi.org/10.1093/molbev/msy230.

88. Zhang $Y$, Zhao J, Zhang H, Gai Y, Wang L, Li F, et al. The involvement of suppressors of cytokine signaling 2 (SOCS2) in immune defense responses of Chinese mitten crab Eriocheir sinensis. Dev Comp Immunol. 2010;34(1): 42-8. https://doi.org/10.1016/j.dci.2009.08.001.

89. Bird TD, Stranahan S, Sumi SM, Raskind M. Alzheimer's disease: choline acetyltransferase activity in brain tissue from clinical and pathological subgroups. Ann Neurol. 1983;14(3):284-93. https://doi.org/10.1002/ana.41 0140306.

90. Domingo A, Klein C. Genetics of Parkinson disease. Handb Clin Neurol. 2018; 147:211-27. https://doi.org/10.1016/B978-0-444-63233-3.00014-2.

91. Nance MA. Genetics of Huntington disease. Handb Clin Neurol. 2017;144:314. https://doi.org/10.1016/B978-0-12-801893-4.00001-8.

92. Nikolac Perkovic M, Pivac N. Genetic markers of Alzheimer's disease. Adv Exp Med Biol. 2019;1192:27-52. https://doi.org/10.1007/978-981-32-9721-0_3.

\section{Publisher's Note}

Springer Nature remains neutral with regard to jurisdictional claims in published maps and institutional affiliations.

\section{Ready to submit your research? Choose BMC and benefit from:}

- fast, convenient online submission

- thorough peer review by experienced researchers in your field

- rapid publication on acceptance

- support for research data, including large and complex data types

- gold Open Access which fosters wider collaboration and increased citations

- maximum visibility for your research: over $100 \mathrm{M}$ website views per year

At $\mathrm{BMC}$, research is always in progress.

Learn more biomedcentral.com/submissions 